\title{
Publicações do Programa de Pós-Graduação em Direito da Universidade Federal do Rio Grande do Sul PPGDIR./UFRGS
}

\section{Cadernos do Programa de Pós-Graduação em Direito PPGDir./UFRG؛ (Publicação semestral)}

Número I - Março 2004

- Número II - Setembro 2004

\section{Edições Especiais}

- Direito Comparado I - Estudos de Direito Brasileiro -Alemão, 1985.

- Seleção de textos da Obra de Erik Jayme (2ºd.). Vol. I, Nº I, Março 2003.

- Direito Comparado II - Homenagem a Clóvis de Couto e Silva - Argentina e a Faculdade de Direito da UFRGS -Vol. I, N II, Setembro 2003.

- Tecendo Relações - 200 anos de encontros entre Btasil e Japão. Vol. I, № III, Novembro 2003.

- Inserção Internacional - International Publications and Distinctions of the PPGDit./UFRGS (2000/2001/2002/2003). Vol. II, No IV, Junho 2004.

- Cooperação com a University of Texas at Austin e Pace Univetsity New YorkHarmonização da Legislação Ambiental no Mercosul - Vol. II, $N^{\circ} \mathrm{V}$, Agosto 2004. 